\title{
Luminescent ruthenium probe for the determination of acetyl phosphate in complex biological matrices $\dagger$
}

\author{
Mark-Steven Steiner and Axel Duerkop* \\ Received 24th June 2010, Accepted 20th September 2010 \\ DOI: 10.1039/c0an00439a
}

\begin{abstract}
The first probe for the fluorogenic determination of acetyl phosphate (AcP), (bpy) ${ }_{2} \mathrm{Ru}(1,10$ phenanthroline-5,6-dione dioxime) (RuPDO), was prepared and its reaction with AcP was studied in detail. The emission of the weakly luminescent RuPDO is red shifted and strongly enhanced upon reaction with $\mathrm{AcP}$ in the presence of metal cations like $\mathrm{Zn}^{2+}$ or $\mathrm{Cu}^{2+}$. The reaction occurs within 60 min incubation time under highly biocompatible conditions (aqueous buffer of $\mathrm{pH} 7,37^{\circ} \mathrm{C}$ ). A linear dynamic range from 10 to $200 \mu \mathrm{mol} \mathrm{L}{ }^{-1}$ is observed with an LOD of AcP of $3.4 \mu \mathrm{mol} \mathrm{L}-1$ (for RuPDO$\mathrm{Zn})$. Other bio-phosphates studied show only weak interference. Furthermore, the applicability of the probe in complex biological matrices was evaluated.
\end{abstract}

\section{Introduction}

Acetyl phosphate (AcP) is a high energy metabolic compound derived from acetic acid and orthophosphoric acid. It was first found by Lipmann in the early forties of the last century ${ }^{1}$ leading to the discovery of coenzyme A. ${ }^{2}$ Acetyl phosphate was also proposed as a primeval form of metabolic energy currency due to its simple chemical structure and high phosphorylation potential $\left(\Delta G^{0}(\mathrm{AcP}):-43 \mathrm{~kJ} \mathrm{~mol}^{-1}\right.$ and $\left.\Delta G^{0}(\mathrm{ATP}):-31 \mathrm{~kJ} \mathrm{~mol}^{-1}\right)$. $^{3-5}$ Therefore, AcP is primarily found in prokaryotes to serve as a regulatory signal transducer, i.e. in the ATP-dependent proteolysis, ${ }^{6}$ activation of the phosphate regulation, ${ }^{7}$ in motility and chemotaxis expression, ${ }^{8}$ or in the initiation of membrane phospholipid synthesis ${ }^{9}$ of countless microorganisms. The steady state concentration of AcP in wild type E. coli reaches at least 3 mmol L ${ }^{-1}$ (ref. 10) and Wolfe et al. ${ }^{11}$ proved that acetyl phosphate acts as a global sign in E. coli. AcP is also a non-nucleotide substrate for the Ca-ATPase ${ }^{12}$ and an important source for regeneration of ATP. ${ }^{7}$ Recently, the presence of an acetate kinase-phosphotransacylase-pathway (involving acetyl phosphate) was also validated for some eukaryotic microbe species. ${ }^{13}$ Up to date, there is no clear evidence that AcP is a stable metabolic intermediate in higher living organisms. On the one hand, enzymes permitting the production of acetyl phosphate from citric acid for example are found in animal tissues. ${ }^{14}$ On the other hand, also highly active acetylphosphatase is present in these tissues. ${ }^{15}$ Furthermore, acetate - the prokaryotic metabolic product of AcP breakdown - is generated endogenously in

Institute of Analytical Chemistry, Chemo- and Biosensors, University of Regensburg, 93040 Regensburg, Germany. E-mail: axel.duerkop@, chemie.uni-r.de; Fax: +499419434064

$\dagger$ Electronic supplementary information (ESI) available: Effect of Zn-concentration on luminescence intensity; testing of RuPDO in different complex biological matrices. See DOI: 10.1039/c0an00439a mammalian cells from acetyl-CoA hydrolase without using AcP. ${ }^{16}$ There might also be a chance of retrieving acetyl phosphate in those cells considering the Warburg hypothesis ${ }^{17}$ that tumor cells generate their energy mainly by non-oxidative breakdown of glucose followed by lactic acid fermentation. In 2009, this hypothesis could be confirmed with VA13 cells by Engler et al. $^{18}$ Further assuming that non-malign cells do not produce and preserve AcP in high concentrations, it might be a powerful tumor marker. AcP attracted some attention in the commercial synthesis of ATP via acetate kinase. This system also provides a cheap and stable source for regeneration of ATP in bacterial batch reactors. ${ }^{19,20}$

Up to date, the most common methods for the determination of acetyl phosphate are the colorimetric hydroxylaminolysis and some acetate kinase (AcK) coupled enzymatic methods. The hydroxamate assay was originally developed by Lipmann and Tuttle $^{21}$ and frequently optimized, among others, by Rose ${ }^{22}$ and Pechère and Capony. ${ }^{23}$ Briefly, AcP is reacted with hydroxylamine and the hydroxamic acid formed reacts with ferric ions to form an orange colored complex. This assay is simple and fast but requires strongly acidic $\mathrm{pH}$ and high concentrations of hydroxylamine (704 $\mathrm{mM})$. This is not suitable for direct analysis of biological samples. Its limit of detection (LOD) is about $40 \mu \mathrm{mol} \mathrm{L}{ }^{-1}$. Recently, this assay was coupled to an enzymatic reaction overcoming some of these limitations. ${ }^{24} \mathrm{AcP}$ is hydrolyzed by lowly concentrated hydroxylamine. The inorganic phosphate produced is then determined with a commercially available $\mathrm{kit}^{25}$ using a purine nucleoside phosphorylase to yield a product absorbing at $330 \mathrm{~nm}$ at $\mu$ molar concentrations of AcP. The main drawback of this assay is that the presence of high concentrations of inorganic phosphate $(\mathrm{Pi})$ in samples prevents direct AcP determination. Further on, Prüß and Wolfe $^{26}$ presented an AcK-based assay wherein the ATP formed is determined by the Luciferase reaction. ${ }^{27}$ This assay was further improved by Ito et $a l^{28}$ and 
Zhao et al. ${ }^{29}$ Another sensitive, yet time consuming method utilizing AcK involves the conversion of acetyl phosphate with radioactive $\left[{ }^{3} \mathrm{H}\right] \mathrm{ADP}$ to $\left[{ }^{3} \mathrm{H}\right] \mathrm{ATP}$, separation by thin layer chromatography (TLC) and scintillation signal readout. ${ }^{30}$ As low as $20 \mathrm{nmol} \mathrm{L}^{-1}$ of AcP were determined. Furthermore, AcP was assayed by supplementing cells with $\left[{ }^{32} \mathrm{Pi}\right]$ and $2 \mathrm{D}-\mathrm{TLC}$ of the cell extract. ${ }^{31}$ Most of these methods share the characteristics that either they are conducted under non-biocompatible conditions or that they are complicated and time consuming.

Our aim was to develop a luminescent method for the direct determination of AcP under biocompatible conditions. We intended to transfer the tunable (e.g. by the addition of $\mathrm{Zn}, \mathrm{Cu}$, $\mathrm{Ni}$, and $\mathrm{Co}$ ) and selective reaction of hydroxylamines or hydroxamic acids ${ }^{32,33}$ to a luminescent reporter molecule. Ruthenium complexes are known to have interesting spectral properties, e.g. large Stokes' shift, high photostability and good quantum yields. Hence, we found (bpy) ${ }_{2} \mathrm{Ru}(1,10$-phenanthroline-5,6-dione dioxime) (RuPDO) to be an interesting candidate for further investigations. We show that upon reaction with $\mathrm{AcP}$ in the presence of $\mathrm{Zn}^{2+}$ or $\mathrm{Cu}^{2+}$ a strong increase in luminescence intensity is accompanied by a bathochromic shift. This selective reaction occurs under highly biocompatible conditions and enables determination of AcP down to the low $\mu \mathrm{mol} \mathrm{L}{ }^{-1}$ range. Although RuPDO does not emit from an excited singlet state, we refer to it as a fluorogenic probe as this is a much more common term than a luminogenic probe. Furthermore, we show the high potential of RuPDO for determination of acetyl phosphate in complex biological matrices.

\section{Experimental}

\section{Instrumentation}

Absorption spectra were recorded on a Cary 50 Bio UV-Vis Spectrophotometer (Varian, Australia, www.varianinc.com). Luminescence spectra were recorded on an Aminco-Bowman AB 2 luminescence spectrometer (www.thermo.com) equipped with a $150 \mathrm{~W}$ continuous wave xenon lamp as excitation light source. All spectra are uncorrected. Lifetime measurements were done on an ISS K2 multifrequency cross-correlation phase modulation fluorimeter (www.iss.com) using an argon ion laser for excitation. Microtiter plate experiments were performed on a Tecan Genios Plus Reader (www.tecan.de) at $\lambda_{\text {exc }}=485 \mathrm{~nm}$ and $\lambda_{\mathrm{em}}=635 \mathrm{~nm}$ in black flat bottom 96 well plates from Greiner Bio-One (www.gbo.com). $\mathrm{pH}$ was measured with a $\mathrm{pH}$ meter $\mathrm{CG}$ 842 from Schott (www.schott.com) at room temperature. The ESI mass spectra were taken on a ThermoQuest TSQ 7000 (www.thermo.com) mass spectrometer. IR spectra of solids were recorded with a diamond ATR-crystal on a Varian 670-IR spectrometer (www.varianinc.com).

\section{Materials}

cis-Dichlorobis(2,2'-bipyridine)ruthenium(II) dihydrate (Ru(bpy) ${ }_{2} \mathrm{Cl}_{2}$ ) was purchased from ABCR (www.abcr.de). All other chemicals and solvents were purchased from Sigma Aldrich (www.sigmaaldrich.com) or Acros Organics (www.acros.be). Stock solutions of acetyl phosphate $\left(10.0\right.$ or $\left.1.0 \mathrm{mmol} \mathrm{L}^{-1}\right)$ were prepared in HEPES buffer of $\mathrm{pH} 7.4\left(40 \mathrm{mmol} \mathrm{L}^{-1}\right)$ shortly before measurements. Stock solutions of RuPDO $\left(1.0 \mathrm{mmol} \mathrm{L}^{-1}\right)$ were prepared by pre-dissolving of $0.94 \mathrm{mg}$ of the reagent in $10 \mu \mathrm{L}$ of DMSO followed by dilution with HEPES buffer to $1.0 \mathrm{~mL}$. The RuPDO stock solution was stored at $4{ }^{\circ} \mathrm{C}$. Stock solutions of $\mathrm{ZnCl}_{2}$ were prepared by dissolving $34.1 \mathrm{mg}$ of the reagent in $50 \mathrm{~mL}$ of HEPES buffer.

\section{Synthesis of RuPDO}

RuPDO was synthesized with slight modifications according to the literature procedure ${ }^{34,35}$ in good yields. $\mathrm{Ru}(\mathrm{bpy})_{2} \mathrm{Cl}_{2}$ (74 mg) was dissolved in dry ethanol $(10 \mathrm{~mL})$, then 1,10-phenanthroline5,6-dione (phendione) ( $29 \mathrm{mg}$ ) was added and the violet solution heated to reflux for $5 \mathrm{~h}$ under $\mathrm{N}_{2}$. After cooling to room temperature, the solvent was removed via rotary evaporation. $\mathrm{Ru}(\mathrm{bpy})_{2}$ (phendione) was redissolved in ethanol $(15 \mathrm{~mL}), \mathrm{CaCO}_{3}$ (dried, $34 \mathrm{mg}$ ) added and the mixture was heated to $81{ }^{\circ} \mathrm{C}$. A solution of $\mathrm{NH}_{2} \mathrm{OH} \cdot \mathrm{HCl}(53 \mathrm{mg})$ in $5 \mathrm{~mL}$ of ethanol was added dropwise over a period of $1 \mathrm{~h}$, while the orange solution turned to a reddish color. After reflux for $5 \mathrm{~h}$ and cooling to room temperature the solvent was evaporated. The remaining orange to red colored solid was dissolved in a small amount of $\mathrm{H}_{2} \mathrm{O}$ and the complex was precipitated by adding excess of $\mathrm{NH}_{4} \mathrm{PF}_{6}$ (Scheme 1). The red precipitate was washed with few $\mathrm{mL}$ of water and diethyl ether. The crude product $(60 \%$ yield) was recrystallized from acetone (50\% yield). Found: C 38.85, H 3.21, N 11.51. $\mathrm{C}_{32} \mathrm{H}_{24} \mathrm{~F}_{12} \mathrm{~N}_{8} \mathrm{O}_{2} \mathrm{P}_{2} \mathrm{Ru} \cdot 3 \mathrm{H}_{2} \mathrm{O}$ requires $\mathrm{C} 38.53, \mathrm{H} 3.03, \mathrm{~N} 11.23 \%$; $\mathrm{m} / \mathrm{z}$ (ESI) $326.8\left(\mathrm{M}^{2+}, \mathrm{C}_{32} \mathrm{H}_{24} \mathrm{~N}_{8} \mathrm{O}_{2} \mathrm{Ru}\right.$ requires 327.1).

\section{Protocol for determination of AcP}

$50 \mu \mathrm{L}$ of the RuPDO stock solution (final concentration $50 \mu \mathrm{mol}$ $\mathrm{L}^{-1}$ in $40 \mathrm{mmol} \mathrm{L}^{-1}$ HEPES buffer of $\mathrm{pH} \mathrm{7.4)} \mathrm{and} 100 \mu \mathrm{L}$ of $\mathrm{ZnCl}_{2}$ (final concentration $0.5 \mathrm{mmol} \mathrm{L}^{-1}$ ) were added to HEPES buffer of $\mathrm{pH} 7.4\left(40 \mathrm{mmol} \mathrm{L}^{-1}\right)$ containing at least $0.05 \mathrm{mmol} \mathrm{L}^{-1}$ of AcP and made up to $1 \mathrm{~mL}$ (for tests in cuvettes). One-tenth of

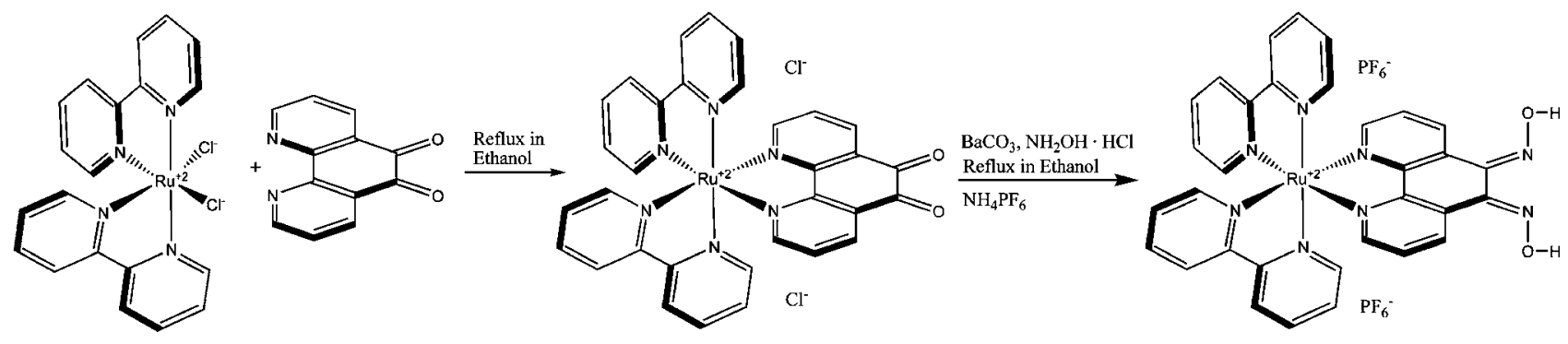

Scheme 1 Synthesis of RuPDO. 


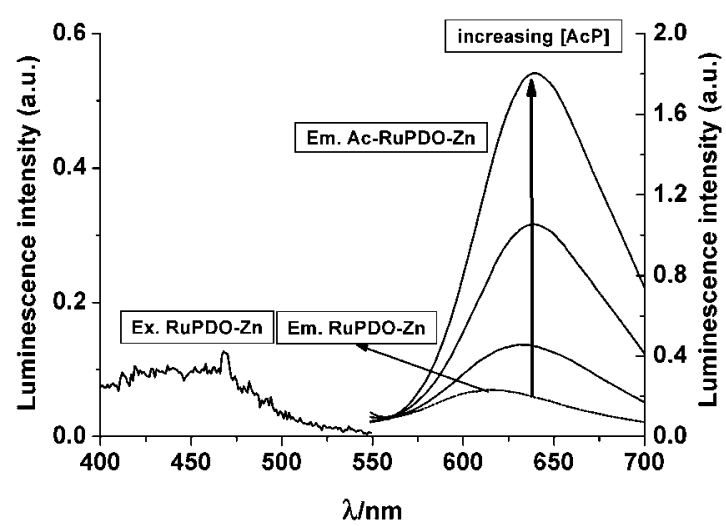

Fig. 1 Excitation spectrum of RuPDO-Zn and emission spectra of RuPDO-Zn and the reaction product with AcP (AcP-RuPDO-Zn) after addition of increasing concentrations of AcP: $50 \mu \mathrm{mol} \mathrm{L}^{-1} \mathrm{RuPDO}, 0.5$ $\mathrm{mmol} \mathrm{L}{ }^{-1} \mathrm{Zn}^{2+}, 20 \mu \mathrm{mol} \mathrm{L}-1,0.1 \mathrm{mmol} \mathrm{L}{ }^{-1}, 0.5 \mathrm{mmol} \mathrm{L}^{-1}$ of AcP, respectively, $40 \mathrm{mmol} \mathrm{L}^{-1}$ HEPES buffer of $\mathrm{pH} 7.4,60$ min incubation at $37{ }^{\circ} \mathrm{C}$. The emission spectrum of RuPDO closely matches the one of RuPDO-Zn and is almost invisible.

Table 1 Spectral properties of RuPDO and the reaction product (AcPRuPDO-Zn)

\begin{tabular}{lll}
\hline & RuPDO & AcP-RuPDO-Zn \\
\hline$\lambda_{\text {exd }} / \mathrm{nm}$ & 469 & 469 \\
$\lambda_{\text {em }} / \mathrm{nm}$ & 610 & 640 \\
$\varepsilon_{430}, \varepsilon_{469} /$ & 7200,5800 & 6300,4400 \\
$\quad \mathrm{~L} \mathrm{~mol}{ }^{-1} \mathrm{~cm}^{-1}$ & & \\
$\Phi^{a}$ & $0.64 \%$ & $4.5 \%$ \\
$\tau^{b}$ & $\tau_{1}: 351 \mathrm{~ns}(81.6 \%)$ & $\tau_{1}: 280 \mathrm{~ns}(19.6 \%)$ \\
& $\tau_{2}: 81 \mathrm{~ns}(16.3 \%)$ & $\tau_{2}: 149 \mathrm{~ns}(80.4 \%)$ \\
& $\left(\chi^{2}=2.5\right)$ & $\left(\chi^{2}=2.1\right)$
\end{tabular}

${ }^{a}$ In air saturated ethanol; reference: Rhodamine $6 \mathrm{G}(\Phi=0.95) .{ }^{b}$ In air saturated HEPES buffer (40 $\left.\mathrm{mmol} \mathrm{L}^{-1}, \mathrm{pH} 7.4\right)$.

all volumes were used for microtiter plate based experiments (final volume $0.1 \mathrm{~mL}$ ). The same amount of RuPDO and $\mathrm{ZnCl}_{2}$ was added to the control containing no AcP. The reaction vials were then kept at $37^{\circ} \mathrm{C}$ for 60 min before measuring luminescence.

\section{Results and discussion}

\section{Spectral properties and response to $\mathrm{AcP}$}

A solution of RuPDO in aqueous buffer shows only weak luminescence $\left(\lambda_{\text {exc/em }}\right.$ at $\left.469 / 610 \mathrm{~nm}\right)$. For determination of acetyl phosphate, the vic-oxime groups of the phenanthroline ligand are activated in situ by the addition of cations like $\mathrm{Zn}^{2+}$, $\mathrm{Cu}^{2+}$ or $\mathrm{Ni}^{2+}$. The addition of these activators does not alter the emission spectrum of RuPDO. The luminescence spectra of RuPDO with (RuPDO-Zn) and without activator cation (RuPDO) and in the presence of AcP (AcP-RuPDO-Zn) are shown in Fig. 1.

A red shift of the emission of RuPDO of $30 \mathrm{~nm}$ (from $610 \mathrm{~nm}$ to $640 \mathrm{~nm}$ ) is observed in the presence of AcP. This is also accompanied by a strong enhancement of fluorescence intensity, increase of quantum yield and change of decay time (see Table 1). The wavelength of the excitation maximum remains unchanged. These spectroscopic changes solely occur in the presence of transition metal cations and active acetic acid esters like AcP or 4-nitrophenyl acetate (4 NA). This effect is not observed in the presence of $\mathrm{Ca}^{2+}$ or $\mathrm{Mg}^{2+}$ (data not shown). Hence, a proposed reaction mechanism is shown in Scheme 2 and evidence for the mechanism is given in a later section.

A further benefit of RuPDO is the large Stokes' shift of $141 \mathrm{~nm}$ (RuPDO-Zn) and $171 \mathrm{~nm}$ (AcP-RuPDO-Zn), respectively. This warrants excellent blocking of excitation light in filter-based fluorescence instrumentation. The fairly strong red fluorescence of AcP-RuPDO-Zn also permits measurements in biological samples with almost zero background. Furthermore, the reaction product can easily be distinguished from the probe itself as the former shows much stronger and red shifted (by $30 \mathrm{~nm}$ ) emission.

The longwave emission of AcP-RuPDO-Zn suggests further investigations for detection of AcP in vivo, where emission at $>600 \mathrm{~nm}$ is a prerequisite to avoid autofluorescence from tissue and warrants suitable penetration depth (due to reduced absorption of tissue).

\section{Choice of activating cation}

Several cations were screened for their oxime activation properties (Table 2). The reaction of RuPDO with AcP was carried out in HEPES buffer, pH $7.4\left(40 \mathrm{mmol} \mathrm{L}^{-1}\right)$, at $37{ }^{\circ} \mathrm{C}$ in the presence of $1 \mathrm{mmol} \mathrm{L}^{-1}$ of AcP, $0.5 \mathrm{mmol} \mathrm{L}^{-1}$ of activating cation and $50 \mu \mathrm{mol} \mathrm{L}^{-1}$ of RuPDO. The luminescence intensity at 640 $\mathrm{nm}$ was referenced with respect to the signal found for $\mathrm{Zn}^{2+}$ activation at $640 \mathrm{~nm}$ after $60 \mathrm{~min}$ incubation time. Finally, only $\mathrm{Zn}^{2+}$ and $\mathrm{Cu}^{2+}$ were selected for further investigations due to their higher biocompatibility compared to the other cations tested and the strong response to AcP.

\section{Effect of $\mathrm{pH}$ and reaction time}

The effect of $\mathrm{pH}$ on the reaction of $\mathrm{Zn}^{2+}$ - and $\mathrm{Cu}^{2+}$-activated RuPDO with AcP was investigated via luminescence measurement at $640 \mathrm{~nm}$. The $\mathrm{pH}$ dependence of the reaction of RuPDO-Zn and RuPDO-Cu with AcP is shown in Fig. 2. It is in good correlation to previous data of $\mathrm{Cu}^{2+}$ and $\mathrm{Zn}^{2+}$ activated oximes. ${ }^{36,37}$ It is possible to determine AcP at physiological $\mathrm{pH}$ with RuPDO-Zn as well as with RuPDO-Cu. Therefore, $\mathrm{pH} 7.4$ was chosen as the optimal $\mathrm{pH}$ for all further investigations.

The reaction rate of $50 \mu \mathrm{mol} \mathrm{L}{ }^{-1} \mathrm{RuPDO}$ in the presence of 0.5 mmol $\mathrm{L}^{-1} \mathrm{Zn}^{2+}$ or $\mathrm{Cu}^{2+}$ with $0.1,0.2$ and $1 \mathrm{mmol} \mathrm{L}^{-1}$ of AcP, respectively, was also examined at $37{ }^{\circ} \mathrm{C}$ via $F / F_{0}$ at $640 \mathrm{~nm}$ (Fig. 3). After $60 \mathrm{~min}$ incubation, over $90 \%$ of the maximum signal is achieved at all concentrations of AcP. Therefore, a $1 \mathrm{~h}$ incubation time was chosen for all further investigations.

\section{Mechanism of fluorogenic reaction}

We were further interested in the mechanism of the reaction between RuPDO-Zn and AcP. The proposed reaction mechanism (Scheme 2) was inspired by the works of Lipmann and 


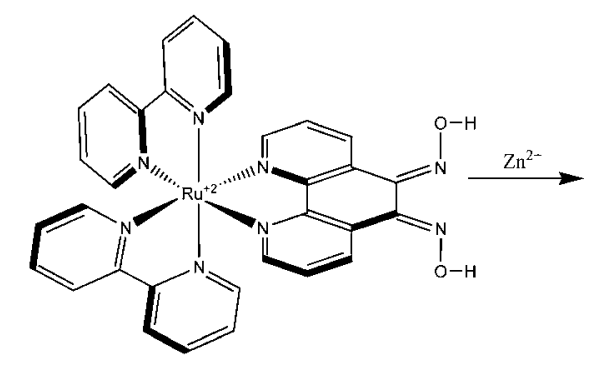

RuPDO

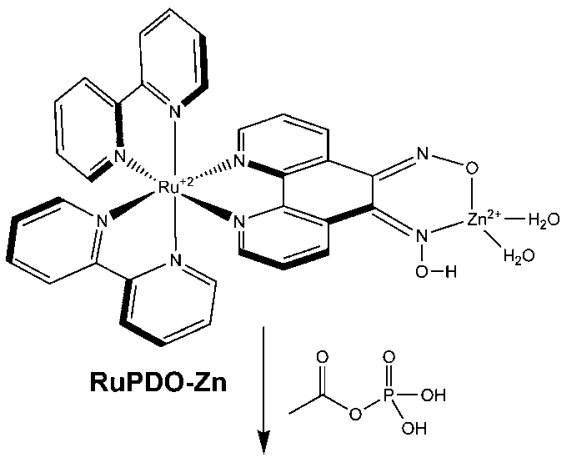

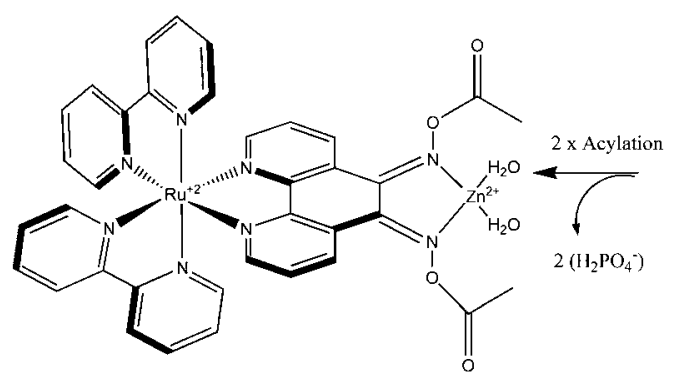

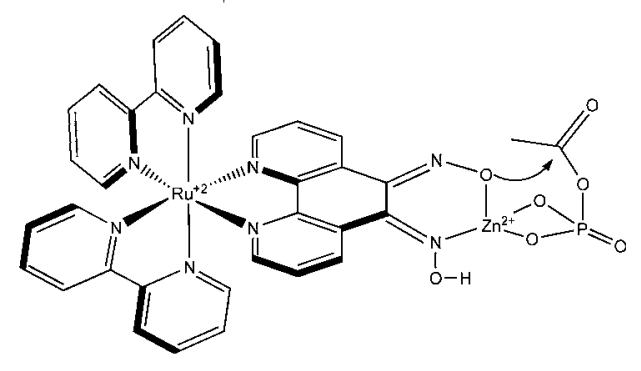

AcP-RuPDO-Zn

Scheme 2 Reaction mechanism of RuPDO-Zn with AcP.

Table 2 Effect of activating cations

\begin{tabular}{lcll}
\hline Activator cation & $I_{\mathrm{M}}{ }^{x+} / I_{\mathrm{Zn}}{ }^{2+a}$ & Activator cation & $I_{\mathrm{M}}{ }^{x+} / I_{\mathrm{Zn}^{2+}}$ \\
\hline $\mathrm{Zn}^{2+}$ & $100 \%$ & $\mathrm{Ce}^{4+}$ & $17 \%$ \\
$\mathrm{Cu}^{+}$ & $52 \%$ & $\mathrm{Ce}^{3+}$ & $66 \%$ \\
$\mathrm{Cu}^{2+}$ & $87 \%$ & $\mathrm{La}^{3+}$ & $39 \%$ \\
$\mathrm{Cd}^{2+}$ & $51 \%$ & $\mathrm{Ni}^{2+}$ & $86 \%$ \\
$\mathrm{Pd}^{2+}$ & $13 \%$ & $\mathrm{Yb}^{3+}$ & $54 \%$ \\
$\mathrm{Ru}^{3+}$ & $13 \%$ & $\mathrm{Y}^{3+}$ & $58 \%$ \\
$\mathrm{Cr}^{2+}$ & $13 \%$ & $\mathrm{~Tb}^{3+}$ & $53 \%$ \\
$\mathrm{Ag}^{++}$ & $18 \%$ & $\mathrm{Eu}^{3+}$ & $46 \%$ \\
$\mathrm{Co}^{2+}$ & $14 \%$ & &
\end{tabular}

${ }^{a}$ After 60 min incubation time, each.

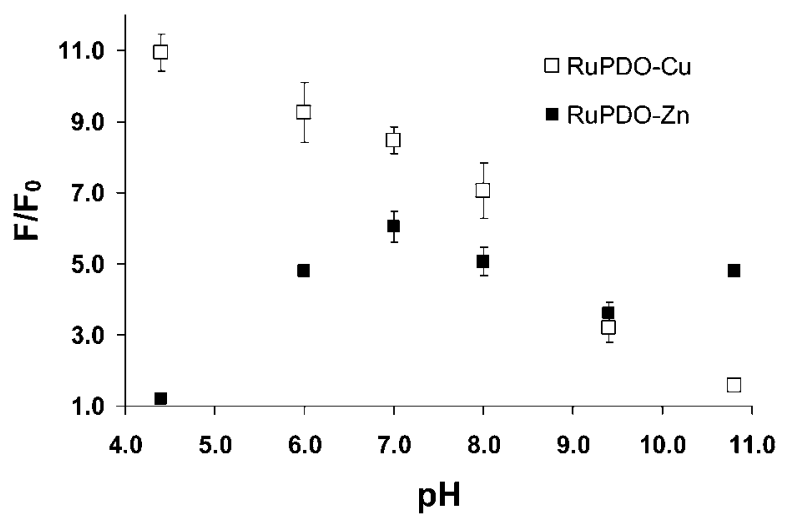

Fig. 2 Effect of $\mathrm{pH}$ on the reaction of RuPDO- $\mathrm{Zn} / \mathrm{Cu}$ with AcP. 10 mmol L ${ }^{-1}$ piperacine-glycylglycine buffer, $50 \mu \mathrm{mol} \mathrm{L} \mathrm{L}^{-1} \mathrm{RuPDO}, 0.5$ mmol L ${ }^{-1} \mathrm{ZnCl}_{2}$ or $\mathrm{CuCl}_{2}$, respectively, $1 \mathrm{mmol} \mathrm{L}{ }^{-1} \mathrm{AcP}, 60 \mathrm{~min}$ incubation at $37^{\circ} \mathrm{C}(n=4)$.

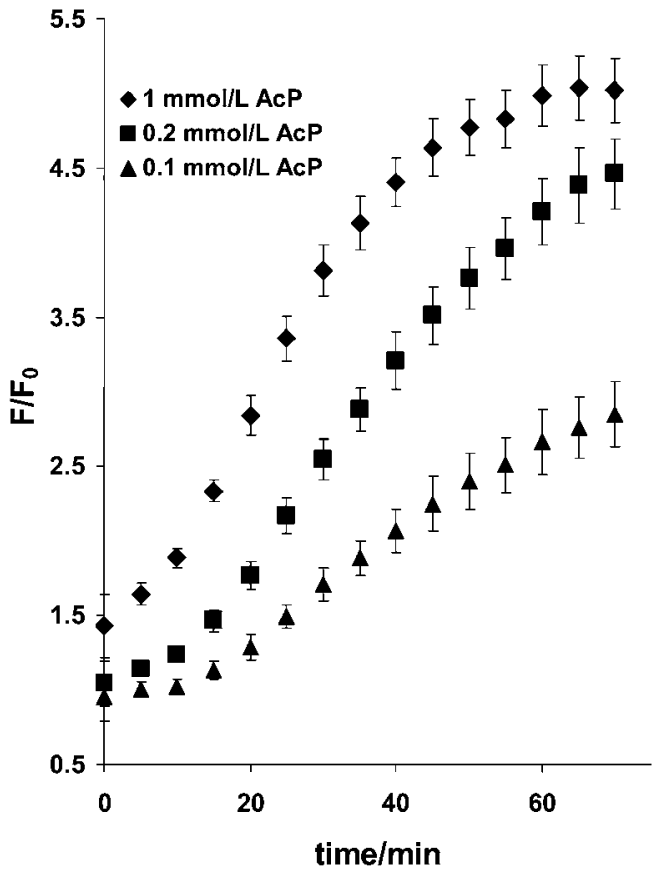

Fig. 3 Effect of reaction time on the reaction of RuPDO-Zn with AcP. $40 \mathrm{mmol} \mathrm{L}^{-1}$ HEPES buffer of $\mathrm{pH} 7.4,50 \mu \mathrm{mol} \mathrm{L}{ }^{-1}$ RuPDO, $0.5 \mathrm{mmol}$ $\mathrm{L}^{-1} \mathrm{Zn}^{2+}, 0.1,0.2$, and $1 \mathrm{mmol} \mathrm{L}^{-1}$ of AcP, respectively, 60 min reaction at $37^{\circ} \mathrm{C}(n=4)$.

Tuttle, ${ }^{21}$ Weijnen et al. ${ }^{38}$ and Mancin et al. ${ }^{39}$ The two main possibilities clearly are either an acetylation of the oxime groups or a phosphorylation. Therefore, we added 4-nitrophenyl acetate (4 NA) to a buffered solution of RuPDO-Zn and in another experiment bis(nitrophenyl) phosphate (BNPP). In case of 1 mmol L ${ }^{-1} 4 \mathrm{NA}$, the same increase of luminescence intensity 


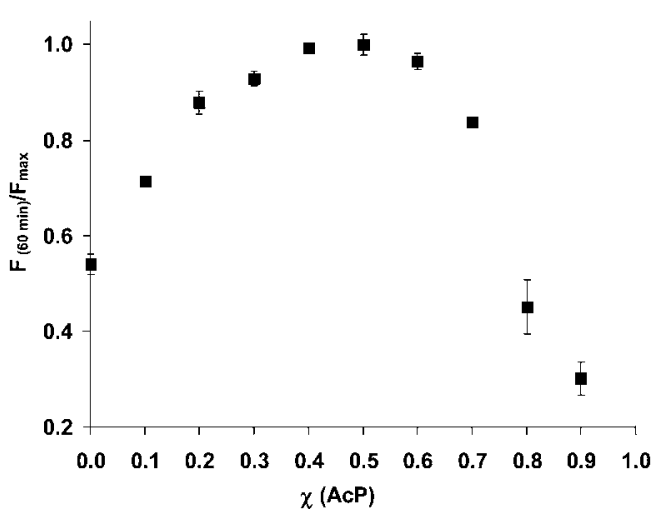

Fig. 4 Normalized fluorescence at $640 \mathrm{~nm} v$ s. mole fraction AcP. Data collected after $60 \mathrm{~min}$ of incubation at $37^{\circ} \mathrm{C}$ in $40 \mathrm{mmol} \mathrm{L}{ }^{-1}$ HEPES of pH $7.4(n=4)$.

peaking at $640 \mathrm{~nm}$ was observed as with AcP solution of equal concentration. Additionally, an increase of the absorbance at 400 $\mathrm{nm}$ was found due to absorption of the 4-nitrophenolate anion formed during the reaction. Neither the emission spectrum nor the absorption spectrum was affected during reaction of RuPDO-Zn with BNPP or other biologically relevant phosphates like inorganic phosphate $(\mathrm{Pi})$, pyrophosphate (PP), ATP and ADP. This is a clear evidence for the oxime acetylation thesis. Furthermore, the IR spectra of RuPDO prior and after reaction with AcP (AcP-RuPDO-Zn) differ mainly due to the appearance of the new aliphatic $\mathrm{C}-\mathrm{H}$ stretching vibrations at 2923 and $2853 \mathrm{~cm}^{-1}$, respectively, of the O-Ac group (AcPRuPDO-Zn).

\section{Complex stoichiometry and calibration plots}

The stoichiometry of the reaction was determined via Job's method of continuous variation. From Fig. 4, a $1: 1$

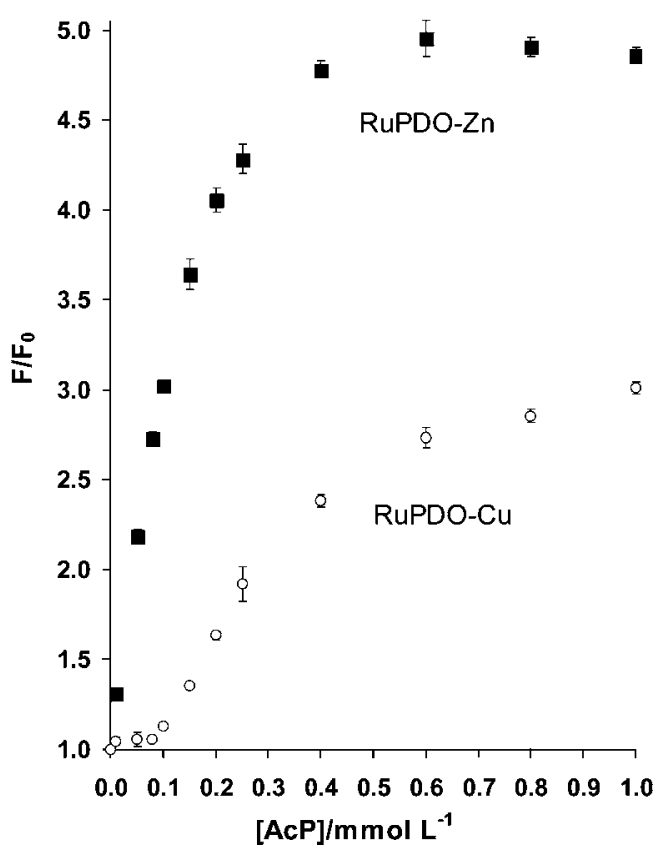

Fig. 5 Plot of $F / F_{0} v s$. [AcP] collected after $60 \mathrm{~min}$ of incubation at $37^{\circ} \mathrm{C}$ in $40 \mathrm{mmol} \mathrm{L}^{-1}$ HEPES of $\mathrm{pH} 7.4(n=4)$. stoichiometry of the reaction of RuPDO-Zn and AcP under the given reaction conditions can be deduced. However, one can assume that in the presence of excess acetyl phosphate both oxime groups of RuPDO will be involved in the reaction. This behavior was observed in the calibration plots in Fig. 5. The fact that linearity of the calibration plot exceeds equimolar concentrations between AcP and RuPDO suggests the participation of the second oxime reaction site. A linear dynamic range from 10 to $200 \mu \mathrm{mol} \mathrm{L}^{-1}$ of AcP and 80 to $400 \mu \mathrm{mol} \mathrm{L}{ }^{-1}$ of AcP at a probe concentration of $50 \mu \mathrm{mol} \mathrm{L}{ }^{-1}$ is observed for RuPDO-Zn and RuPDO-Cu, respectively. The regression equation for RuPDO$\mathrm{Zn}$ is $F / F_{0}=16.59 \mathrm{~L} \mathrm{mmol}^{-1}[\mathrm{AcP}]+1.29(r=0.990)$ and $F / F_{0}=$ $4.28 \mathrm{~L} \mathrm{mmol}^{-1}[\mathrm{AcP}]+0.74(r=0.990)$ for RuPDO-Cu. The limit of detection of AcP via RuPDO-Zn is $3.4 \mu \mathrm{mol} \mathrm{L}{ }^{-1}$. Hence, AcP can be determined at least at 10 times lower concentrations compared to the method of Lipmann and Tuttle. ${ }^{21}$

\section{Interference of other relevant phosphates}

The reaction of RuPDO-Zn with AcP in the presence of equimolar concentrations of inorganic phosphate $(\mathrm{Pi})$, pyrophosphate (PP) and ATP was monitored using luminescence (Fig. 6). These phosphates slightly quench the luminescence of RuPDO$\mathrm{Zn}$, probably due to coordination to $\mathrm{Zn}^{2+}$. Within a tolerance limit of $\pm 10 \%$ the following concentrations of interferents are acceptable: $\mathrm{Pi}=1 \mathrm{mmol} \mathrm{L}{ }^{-1}, \mathrm{PP}=0.22 \mathrm{mmol} \mathrm{L}^{-1}$ and ATP $=$ $0.67 \mathrm{mmol} \mathrm{L}^{-1}$. Hence, even in the presence of equimolar concentrations of AcP and phosphate $\left(1 \mathrm{mmol} \mathrm{L}^{-1}\right.$ as found in DMEM medium, see next section) a pronounced increase of luminescence is detectable. As a result, the slope of a calibration plot for AcP in the presence of equimolar phosphate is slightly reduced. We assume that binding of these phosphates to RuPDO-Zn blocks the "binding-site" for AcP, resulting in a lower acetylation-rate and therefore a lower luminescence. Addition of phosphate to a reacted solution (90 min) of AcPRuPDO-Zn does not change the signal (data not shown), substantiating the binding-site-blocking thesis. The binding of phosphates to the probe can adequately be reduced by adding a higher amount of $\mathrm{Zn}^{2+}$ to the sample, resulting in higher luminescence intensity due to complexation of phosphate by free

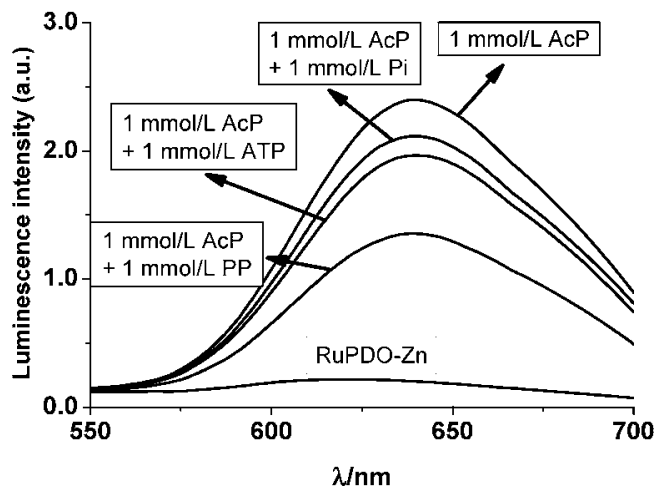

Fig. 6 Effect of bio-phosphates on the luminescence of the reaction of RuPDO-Zn with AcP. 40 mmol L ${ }^{-1}$ HEPES buffer of $\mathrm{pH} 7.4,50 \mu \mathrm{mol}$ $\mathrm{L}^{-1} \mathrm{RuPDO}, 0.5 \mathrm{mmol} \mathrm{L}^{-1} \mathrm{Zn}^{2+}, 1 \mathrm{mmol} \mathrm{L}{ }^{-1}$ of AcP and inorganic phosphate (Pi), pyrophosphate (PP), ATP, each, 60 min reaction at $37^{\circ} \mathrm{C}$ $(n=4)$. 
$\mathrm{Zn}^{2+}$ in solution (Fig. $\mathrm{S} 1 \dagger$ ). It is obvious from Fig. $\mathrm{S} 1 \dagger$ that higher concentrations of $\mathrm{Zn}^{2+}$ are able to overcome the quenching-effect of Pi.

\section{Tests of RuPDO-Zn in cell medium containing NRK cells}

The reaction of RuPDO-Zn with AcP was examined in Dulbecco's Modified Eagle Medium (DMEM) and also in DMEM medium containing normal rat kidney (NRK) cells in order to test the future applicability of the probe for measurements in biological matrices. DMEM medium used in the experiments contains, among others, high millimolar concentrations of inorganic compounds like $\mathrm{CaCl}_{2}, \mathrm{NaH}_{2} \mathrm{PO}_{4}$ and $\mathrm{KCl}$, various amounts of different amino acids and $10 \%(\mathrm{w} / \mathrm{w})$ fetal calf serum. NRK cells were grown in DMEM medium for 2 days. During this period the medium is further enriched with products of cell metabolism. Hence, the cell medium used is a complex matrix and served as reaction medium without further workup. The medium together with $50 \mu \mathrm{mol} \mathrm{L}{ }^{-1}$ of RuPDO, $0.5 \mathrm{mmol} \mathrm{L}^{-1}$ $\mathrm{ZnCl}_{2}$ and various amounts of $\mathrm{AcP}$ was incubated at $37^{\circ} \mathrm{C}$ and the progress of the reaction was monitored for $90 \mathrm{~min}$ by recording the increase of the luminescence intensity at $640 \mathrm{~nm}$. An almost 2.5 fold signal increase in both DMEM medium containing NRK cells (Fig. 7) and medium without cells (data not shown) was observed on addition of $2 \mathrm{mmol} \mathrm{L}^{-1}$ of AcP. As a matter of fact, the signal increase is not as high as observed in plain aqueous buffered solution due to the complex matrix. The slope is reduced by a factor of 20 compared to aqueous buffer. However, it is obvious from the calibration plot that determination of AcP from 0.5 to $2 \mathrm{mmol} \mathrm{L}^{-1}$ is possible with reasonable precision in complex biological matrices using the luminescence of RuPDO-Zn. Importantly, the reaction time in cell medium is much shorter compared to the reaction in aqueous buffer. The maximum luminescence intensity at $640 \mathrm{~nm}$ is obtained after

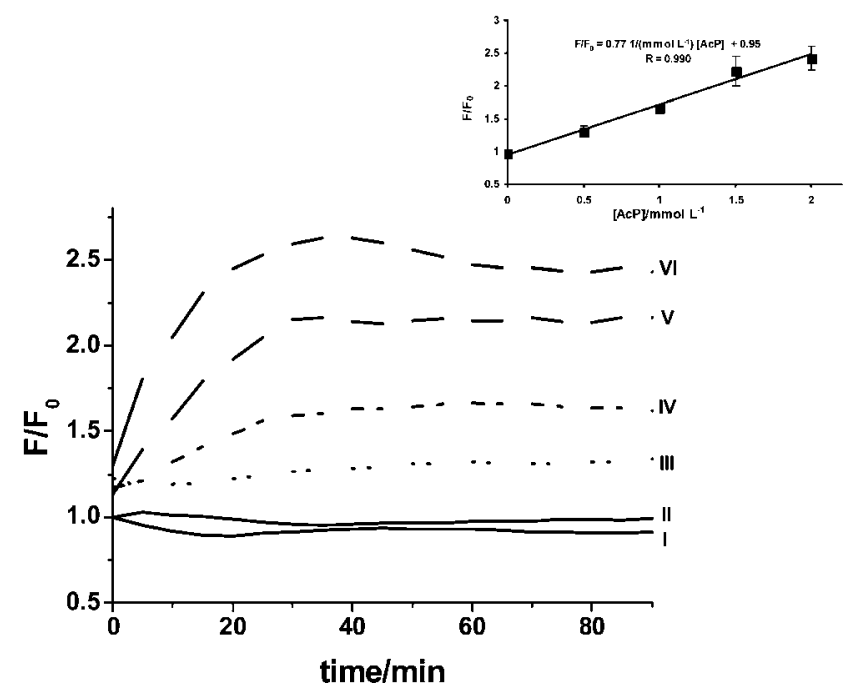

Fig. 7 Luminescence of RuPDO-Zn in suspensions of NRK cells in DMEM cell medium after spiking with AcP. Solid lines (I and II) represent unspiked samples without cells (I) and in the presence of cells (II). Dashed lines (III to VI) represent spiked samples of cell media containing NRK cells. AcP concentration is increasing from $0.5 \mathrm{mmol}$ $\mathrm{L}^{-1}$ (III) to $2 \mathrm{mmol} \mathrm{L}^{-1}$ (VI) $(n=4)$.
$30 \mathrm{~min}$ of incubation. This strongly supports the proposed reaction mechanism of RuPDO-Zn. A high amount of RuPDO$\mathrm{Zn}$ is already blocked in the presence of high concentrations of phosphate. Therefore, only few RuPDO-Zn molecules are able to react with AcP, resulting in an decreased luminescence intensity at $640 \mathrm{~nm}$ and shorter reaction time compared to a sample in plain buffer.

Additional tests of RuPDO-Zn were conducted in E. coli lysogeny broth (LB) media without bacteria, in LB media containing E. coli, and in LB media containing sonicated E. coli (see ESI $\dagger$ ). The kinetic of the reaction of RuPDO-Zn with AcP in E. coli LB media without bacteria is shown in Fig. S2†. The reaction of RuPDO-Zn with AcP is slower than in DMEM medium (Fig. 7). While the increase of luminescence intensity is slower, the slope of the calibration plot is steeper (Fig. S3 $\dagger$ ) than in DMEM medium (inset of Fig. 7). The kinetic of the reaction of RuPDO-Zn with AcP in LB media containing E. coli is shown in Fig. $\mathrm{S} 4 \dagger$ and remains almost unchanged with respect to $\mathrm{LB}$ medium without $E$. coli (Fig. S2 $\dagger$ ). The increase of luminescence intensity is lower, resulting in a lower slope of the calibration plot (Fig. S5 $\dagger$ ) than in LB medium without E. coli (Fig. S3†). This behavior could be expected because cells usually show strong scatter in luminescence measurements. The kinetic of the reaction of RuPDO-Zn with AcP in LB media containing sonicated E. coli is shown in Fig. S6† and remains almost unchanged with respect to LB medium containing E. coli (Fig. S4†). Here, the increase of luminescence intensity (Fig. S7†) is almost constant with respect to the unlysed cells (Fig. S5 $†$ ). These data clearly show the applicability of the probe in various complex biological matrices.

\section{Conclusions}

The first fluorogenic probe RuPDO is introduced for the rapid and direct determination of acetyl phosphate in aqueous solutions at neutral $\mathrm{pH}$. Unlike in common methods for determination of AcP, the presence of millimolar inorganic phosphate only weakly reduces sensitivity and no radioactive waste is produced. Successful determination of AcP in complex biological matrices and the longwave emission of AcP-RuPDO-Zn suggest further investigations for detection of $\mathrm{AcP}$ in vivo. A combination of RuPDO with suitable enzymes involved in the formation or conversion of AcP suggests luminescent probing of other biological important analytes like glucose, $\boldsymbol{\alpha}$-ketoglutarate, and acetate. These experiments are now under way.

\section{Acknowledgements}

MSS gratefully acknowledges financial support from the BMBF (German Ministry for Education and Research) within the Biophotonik II programme for the joint project "TumorVision". We thank Barbara Goricnik from the Bioanalytics and Biosensors group (Prof. Dr. J. Wegener) of our institute for conducting the cell growth experiments.

\section{References}

1 F. Lipmann and C. L. Tuttle, J. Biol. Chem., 1944, 153, 571-582.

2 N. Kresge, R. D. Simoni and R. L. Hill, J. Biol. Chem., 2005, 280, 164-166. 
3 J. G. Ferry and C. H. House, Mol. Biol. Evol., 2006, 23, 1286-1292.

4 C. de Duve, Origins Life Evol. Biosphere, 2003, 33, 559-574.

5 W. Martin and M. J. Russell, Philos. Trans. R. Soc. London, Ser. B, 2007, 362, 1887-1926.

6 I. Mizrahi, D. Biran and E. Z. Ron, Mol. Microbiol., 2006, 62, 201211.

7 S. K. Kim, M. R. Wilmes-Riesenberg and B. L. Wanner, Mol. Microbiol., 1996, 22, 135-147.

8 I. Gueriri, S. Bay, S. Dubrac, C. Cyncynatus and T. Msadek, Mol. Microbiol., 2008, 70, 1342-1357.

9 Y. J. Lu, Y. M. Zhang, K. D. Grimes, J. Qi, R. E. Lee and C. O. Rock, Mol. Cell, 2006, 23, 765-772.

10 A. H. Klein, A. Shulla, S. A. Reimann, D. H. Keating and A. J. Wolfe, J. Bacteriol., 2007, 189, 5574-5581.

11 A. J. Wolfe, Curr. Opin. Microbiol., 2010, 13, 204-209.

12 F. Soler, M. I. Fortea, A. Lax and F. Fernández-Belda, J. Biol. Chem., 2002, 277, 38127-38132.

13 C. Ingram-Smith, S. R. Martina and K. S. Smitha, Trends Microbiol., 2006, 14, 249-253.

14 M. F. Guly, T. N. Pechenova and L. I. Matusevich, Nature, 1966, 212, 36-37.

15 B. Shapiro and E. Wertheimer, Nature, 1945, 156, 690.

16 B. Crabtree, M. J. Souter and S. E. Anderson, Biochem. J., 1989, 257, 673-678.

17 O. Warburg, F. Wind and E. Negelein, J. Mol. Med., 1926, 5, 829832 .

18 I. Engler, C. Atzmüller, V. Donic and F. Steinhäusler, J. Exp. Ther. Oncol., 2009, 8, 157-165.

19 R. L. Baughn, O. Adalsteinsson and G. M. Whitesides, J. Am. Chem. Soc., 1987, 100, 304-306.
20 L. A. Ryabova, L. M. Vinokurov, E. A. Shekhovtsova, Y. B. Alakhov and A. S. Spirin, Anal. Biochem., 1995, 226, 184-186.

21 F. Lipmann and L. C. Tuttle, J. Biol. Chem., 1945, 159, 21-28.

22 I. A. Rose, Methods Enzymol., 1955, 1, 591-595.

23 J. F. Pechère and J. P. Capony, Anal. Biochem., 1968, 22, 536-539.

24 S. Mukhopadhyay, M. S. Hasson and D. A. Sanders, Bioorg. Chem., 2008, 36, 65-69.

25 M. R. Webb, Proc. Natl. Acad. Sci. U. S. A., 1992, 1, 48844887.

26 B. M. Prüß and A. J. Wolfe, Mol. Microbiol., 1994, 12, 973984.

27 A. Lundin and A. Thore, Anal. Biochem., 1975, 66, 47-63.

28 K. Ito, K. Nakagawa, S. Murakami, H. Arakawa and M. Maeda, Anal. Sci., 2003, 19, 105-109.

29 Y. Zhao, C. A. Tomas, F. B. Rudolph, E. T. Papoutsakis and G. N. Bennett, Appl. Environ. Microbiol., 2005, 71, 530-537.

30 A. G. Hunt and J. S. Hong, Anal. Biochem., 1980, 108, 290-294.

31 D. H. Keating, A. Shulla, A. H. Klein and A. J. Wolfe, Biol. Proced. Online, 2008, 10, 36-46.

32 C. H. Oestreich and M. M. Jones, Biochemistry, 1966, 5, 2926-2931.

33 P. J. Briggs, D. P. N. Satchell and G. F. White, J. Chem. Soc. B, 1970, $1008-1012$.

34 S. Bodige and F. M. MacDonnell, Tetrahedron Lett., 1997, 38, 81598160 .

35 M. Li, Z. Xiao, Z. Huan and Z. Lu, Appl. Surf. Sci., 1998, 125, 217-220.

36 F. Mancin, P. Tecilla and U. Tonellato, Langmuir, 2000, 16, 227-233.

37 S. Liu and A. D. Hamilton, Tetrahedron Lett., 1997, 38, 1107-1110.

38 J. G. J. Weijnen, A. Koudijs, G. A. Schellekens and J. F. J. Engbersen, J. Chem. Soc., Perkin Trans. 2, 1992, 829-834.

39 F. Mancin, P. Tecilla and U. Tonellato, Langmuir, 2000, 16, 227-233. 